\title{
FARMED ANIMALS AND THE LAW IN NEW ZEALAND
}

\section{Kari Schmidt}

The New Zealand Animal Law Association (NZALA) was established in 2014 to advocate for animals through the legal system. Kari Schmidt is currently drafting a report on behalf of the NZALA on the law regarding farmed animals in New Zealand. This report considers how the codes of welfare and regulations under the Animal Welfare Act 1999 fail to meet the standards prescribed by the Act. In particular, it examines the codes of welfare and regulations for pigs, dairy cattle, meat chickens, layer hens and the lack of a code of welfare for fish. This report will be released in 2020. This research was generously funded by the New Zealand Law Foundation - Te Manatū a Ture o Aotearoa - an independent charitable trust that provides grants for legal research, public education on legal matters, and legal training.

\section{INTRODUCTION}

Animal Welfare in New Zealand is governed by the Animal Welfare Act 1999 (hereafter, the Act) and by codes of welfare and regulations established under the Act. These codes of welfare and regulations are delegated legislation, meaning they are not enacted by Parliament but by the Ministry of Primary Industries (MPI), to which Parliament has delegated law-making authority. The Act also established the National Animal Welfare Advisory Committee (NAWAC)', whose functions include advising the Minister of Primary Industries on issues relating to welfare of animals; developing codes of welfare and recommending them to the Minister ${ }^{2}$; and providing animal welfare advice to the Minister on regulations to be made under the Act. $^{3}$

The Act sets up an overarching framework in relation to animal welfare law. Lauded both nationally and internationally as highly progressive, it provides for a preventative and proactive approach to animal welfare compared to its historical equivalents (which established provisions only to prevent overt cruelty to animals). Owners and persons in charge of animals are required to ensure that the "physical, health and behavioural needs" of animals are met. ${ }^{4}$ These are defined as proper and sufficient food, proper and sufficient water, adequate shelter, the opportunity to display normal patterns of behaviour, physical handling in a manner which minimizes the likelihood of unreasonable or unnecessary pain or distress, and protection from, and rapid diagnosis of, any significant injury or disease. ${ }^{5}$ These are also known as the "five freedoms" and are now a widely accepted concept within animal welfare theory. ${ }^{6}$

The codes of welfare and regulations established under the Act are intended to supplement the Act through the provision of specific guidelines in relation to particular species or use of animals. ${ }^{7}$ Unfortunately, there appears to be a gap between our ostensibly progressive Act and the delegated legislation established under the Act, with the codes of welfare and regulations failing to adequately provide for the "physical, health and behavioural needs" of farmed animals.

\section{PIGS}

Pigs are a good example. The continued use of farrowing crates for four weeks post-farrowing does not adequately provide for the "physical, health and behavioural needs" of pigs. In particular, the severe spatial restrictions placed 
on pigs in these circumstances means that their ability to express their normal behaviours is extremely limited - in these crates, pigs cannot even step forwards or backwards and cannot turn around.

Historically, the main reason for the use of farrowing crates has been to reduce piglet mortality, with the close confinement of the sow preventing her from rolling or stepping onto her piglets. However, there have been a number of studies published since the code of welfare for pigs was released showing that piglet mortality between crate and pen-based systems are relatively similar ${ }^{8}$, and that other methods can be used to ameliorate piglet mortality in non-crate systems. ${ }^{9}$ Additionally, NAWAC has recently acknowledged that research shows a much shorter period of time in the farrowing crate is feasible, and suggested that "the period after birth that the sow is confined in a crate could be limited to around four days." 10

Space in general is at issue for pigs. The code of welfare provides for an equation to determine the minimum space allowable for pigs based on their body weight." However, this calculation only pertains to minimum allowable "lying space" and does not take into account the amount of space pigs need to exhibit their normal behaviours. Pigs are highly motivated to explore and engage in other behaviours such as rooting and foraging, however, the limited space provided to them under the code of welfare frustrates these behaviours. NAWAC even recognises this in the code of welfare: "Based on emerging international research, NAWAC believes the current industry guidelines for space requirements need to be reviewed as 10\%-50\% more space may be required to provide for all pigs' needs, depending on their level of activity and the thermal conditions." '2 While NAWAC recommends the provision of greater space in the code of welfare, this is not a mandatory requirement.

\section{LAYER HENS}

Colony cages are currently permitted under the code of welfare for layer hens. These cages contain up to 60 hens, with each hen living its life on 750 square centimetres (slightly larger than an A4 piece of paper). NAWAC and MPI have argued that colony cages are an improvement on the battery cages that preceded them, as the hens have more space and a range of artificial enhancements to facilitate their normal behaviours, such as a scratching pad and nesting site. However, the increase in space from 550 square centimetres to 750 square centimetres does not enable these chickens to adequately exhibit their normal behaviours. For example, studies have shown that grouphoused hens "require an average of approximately $475 \mathrm{~cm} 2$ for standing, 540-1005 cm2 for scratching, 77। - 1377 $\mathrm{cm} 2$ for turning, 652-1118 cm2 for wing stretching, 860-1980 cm2 for wing flapping, 676-1604 cm2 for feather ruffling and 814-1270 cm2 for preening."'3 Further, the artificial enhancements provided are insufficient, with up to 60 birds expected to share one scratching pad and one nesting area.

\section{MEAT CHICKENS}

Perhaps the primary welfare issue in relation to meat chickens is selective breeding for fast growth rates, with chickens reaching their slaughter weight of about $2-2.5 \mathrm{~kg}$ at about $5-6$ weeks of age. ${ }^{14}$ The issue applies not only to intensively farmed meat chickens, but to free-range meat chickens as well, which are "still the same genotype."15 Commentators have noted that this rate of growth is a significant departure from how birds were raised historically, with traditional meat chickens taking around 12 weeks to reach their slaughter weight of about 2 kilograms. ${ }^{16}$

The use of fast-growing breeds leads to a range of welfare issues, including heart problems, ascites, sudden death syndrome and leg disorders. ${ }^{17}$ In 2017, NAWAC recognised in a report on selective breeding that "selection for high juvenile growth rate, breast-meat yield and efficiency of feed conversion has left meat chickens vulnerable to welfare problems such as cardiovascular disease, and lameness or difficulty in walking". ${ }^{8}$ However, while NAWAC identified concerns about the welfare implications of high growth rates in the code of welfare for meat chickens ${ }^{19}$, there are no provisions preventing the use of fast-growing breeds or even recommending the use of slow-growing breeds. 
Additionally, meat chickens in New Zealand are highly stocked, with the code permitting $38 \mathrm{~kg}$ of live weight per square metre ${ }^{20}$ - being approximately $15-19$ birds per square metre. ${ }^{21}$ High stocking densities inhibit locomotion and exploration, with meat chickens at high stocking densities spending more time sleeping, congregating around feeders and being more fearful. ${ }^{22}$ High stocking densities result in an inability to move and explore, which leads to conditions such as contact dermatitis. ${ }^{23}$ Birds in such environments are more likely to be exposed to higher ammonia levels, irritating their eyes and respiratory systems. ${ }^{24}$ And it has been shown that high stocking densities lead to an increase in lameness in broiler chickens and to health issues relating to the legs of broiler chickens generally. ${ }^{25}$ A 2013 survey by MPI on lameness in meat chickens recognised that where stocking density is high this is "likely to reduce activity and contribute to an increased prevalence of leg weakness." ${ }^{26}$ Further, high stocking densities have a negative impact on gut health in meat chickens, predisposing chickens to necrotic enteritis. ${ }^{27}$

\section{DAIRY CATTLE}

While the code of welfare for dairy cattle generally provides that these animals have access to areas free of surface water and mud $^{28}$; protection from adverse weather ${ }^{29}$, and that they are able to lie down and rest comfortably for sufficient periods to meet their behavioural needs ${ }^{30}$, winter grazing and the issues associated with it are not specifically addressed in the code of welfare. Winter grazing involves animals being fed during the winter period on forage, such as pasture or crop. Animals are kept on a measured area of forage and once they have finished grazing, are moved to another strip of forage. ${ }^{31}$ This practice has recently been identified by MPI as an animal welfare issue for dairy cattle, with cows being kept in excessively muddy and wet conditions for prolonged durations. To investigate this, MPI formed a "Winter Grazing Taskforce", which released a report on this topic in 2019 identifying numerous animal welfare issues associated with winter grazing. ${ }^{32}$

Additionally, in 2019 NAWAC revised the code of welfare to include minimum standards relating to off-paddock facilities. ${ }^{33}$ The 2019 revisions allow for cows to be kept on off-paddock facilities year-round, subject only to a recommendation that "mature cattle in off-paddock facilities should be given daily voluntary access to pasture or to a suitable outdoor area." 34 NAWAC chair Dr Gwyneth Verkerk has stated that NAWAC wants "dairy cattle that are housed long-term to have access to outdoors, but affected farmers have time to comply". ${ }^{35}$ However, it remains to be seen what future provisions regarding outdoor access will look like, and when they will be implemented. It also seems likely that these future provisions will not require cows to have access to pasture - as NAWAC outlined in its report, dairy cattle would simply have to have access to a "suitable outdoor area... [with] a soft compressible surface and sufficient space that allows a wide range of normal patterns of behaviour including the ability to exercise on soft non-slip surfaces, freedom to choose when to lie down, space and soft surfaces for lying in a range of normal lying positions, and space for grooming and for avoiding aggressive interactions." ${ }^{16}$ This is despite the fact that "cattle prefer pasture access under certain conditions and are motivated to access pasture" ${ }^{\prime \prime}$, and despite the health benefits associated with pasture. These include reductions in: mortality rates, incidence of lameness and mastitis, severe hoof disorders, risk of poor locomotion, incidence of infectious forms of foot disease and metabolic and digestive disorders, among others. ${ }^{38}$

\section{FISH}

The lack of a code of welfare for fish is concerning, as it means there is limited guidance available as to how fish should be farmed in order to ensure their physical, health, and behavioural needs are met. This is particularly problematic given the extent of New Zealand's fishing industry, with approximately 15 thousand metric tonnes of fish harvested from fish farms every year. ${ }^{39}$ There are a range of welfare issues that such a code would need to consider, including in relation to handling, stocking density, holding facilities, bone deformities (a common health issue in farmed fish), veterinary medicines, food, water quality, and lighting. 


\section{FARMED ANIMALS IN NEW ZEALAND}

These are just a few examples of how the standards outlined in a number of the codes of welfare and regulations conflict with the requirement outlined in the Act to meet the "physical, health and behavioural needs" of farmed animals. There are many more. ${ }^{40}$

The inadequacy of our legal regime in regards to farmed animals is particularly problematic, as these animals comprise the bulk of domesticated animals in New Zealand. As at 2016, New Zealanders owned approximately 4.6 million pets. ${ }^{41}$ In contrast, according to recent statistics, New Zealand annually farms approximately 63.55 million dairy cattle ${ }^{42}, 39.22$ million beef cattle ${ }^{43}, 125$ million meat chickens ${ }^{44}, 287$ thousand pigs $s^{45}, 3.69$ million layer hens ${ }^{46}$, and approximately 116 thousand tonnes of seafood. ${ }^{47}$ Given that New Zealand has such high levels of animal production and consumption, there is a particular onus on us to ensure that the welfare of our farmed animals is adequately protected.

Agriculture is also a significant industry in New Zealand, generating around 36 billion dollars a year in exports and constituting around 12\% of New Zealand's GDP.48 New Zealand accounts for around a third of the world's international dairy trade. ${ }^{49}$ It is in this context that high standards of animal welfare, which is recognised as important to overseas consumers, are now a goal of many industry bodies in New Zealand. Given our dependency on the primary sector and agriculture in particular, trade reputation is a strong driver of animal welfare policy in New Zealand and this is outlined in numerous of MPl's policy documents.

Further, high standards of animal welfare are inherently important to many New Zealanders. For instance, in 2017 MPI issued a report on New Zealander's views of the primary sector. Over 95\% of respondents agreed, "It is important that the welfare of farmed animals in New Zealand is protected." ${ }^{0}$ Such attitudes are further reflected in consumer decision-making with increasing numbers of New Zealanders opting to buy free-range, reducing their meat consumption, or converting to a vegan or vegetarian diet.

\section{RECOMMENDATIONS FOR REFORM}

In light of the above, the codes of welfare and regulations are in need of review, such that the standards they prescribe are in keeping with the Act - including the requirement to consider the latest available scientific knowledge and good practice..$^{51}$ Any practices inconsistent with the Act, which cannot be revised immediately, should be turned into regulations under section $183 \mathrm{~A}$ of the Act, subject to the phase-out periods of 5-15 years outlined in this section.

The role of MPI and NAWAC in administering the codes of welfare and regulations are also in need of review, as this discrepancy between the Act and the codes of welfare and regulations appear to be linked to the role these agencies have in administering delegated legislation under the Act. For instance, MPI's primary motivations are to further "export opportunities for our primary industries [and to] improve sector productivity." 52 Thus, animal welfare is at least a secondary priority, if not a competing priority. Additionally, the methodologies adopted by NAWAC in developing the codes have often failed to ensure that the standards prescribed are at least the minimum necessary to ensure the purposes of the Act are met. This is due to an often inadequate and inconsistent review of the available scientific literature, and a failure to adequately consult and engage with the public. There is also a lack of clarity regarding the methodology that NAWAC uses to review the codes. ${ }^{53}$

A review of MPI and NAWAC's administration of the animal welfare law could be undertaken under the auspices of a public or government inquiry. The performance of NAWAC and MPI in relation to animal welfare should also be audited or overseen by another government agency or an independent body so as to provide adequate oversight. Ultimately, the establishment of an adequately funded Independent Commissioner for Animals or an independent committee for animal welfare would be the best approach to ensure that the codes of welfare are robust, up-todate and meet the requirements of the Act. 


\section{CONCLUSION}

The Act has now been in force for over 20 years, with about a decade having passed since each of the codes of welfare for farmed animals were reviewed in full. ${ }^{54} \mathrm{It}$ is critical then that the implementation of the Act through these delegated instruments be assessed closely. A comprehensive review of the codes of welfare and regulations, as well as the processes by which they were established by MPI and NAWAC, are an important and overdue step in ensuring that New Zealand does have world-leading standards of animal welfare that honour what is enshrined in the Act.

Kari Schmidt is a Solicitor in the Disputes Resolution team at Gallaway Cook Allan in Dunedin. She also has a sustained interest in research, animal welfare law, art writing and curating, zines and meditation.

I Animal Welfare Act 1999, section 56.

2 lbid, section 57.

3 Ibid, section $183 \mathrm{~A}(10)$.

4 Ibid, section 10

5 Ibid, section 4.

6 The "five freedoms" are the freedom from hunger or thirst; freedom from discomfort; freedom from pain, injury or disease; freedom to express (most) normal behaviour and freedom from fear and distress. The "five freedoms" is a concept fundamental to animal welfare theory, with its origin in the 1965 Brambell Committee Report: R Brambell, Report of the Technical Committee to Enquire into the Welfare of Animals Kept Under Intensive Husbandry Systems (London: Cmnd 2836, HMSO, 1965). The "five freedoms" have been adopted by veterinarians as well as animal welfare organisations such as the RSPCA, the World Organisation for Animal Health and the American Society for the Prevention of Cruelty to Animals.

7 There are currently 19 codes of welfare relating to circuses, cats - pet or companion, dairy cattle, deer, dogs, goats, horses and donkeys, layer hens, llamas and alpacas, meat chickens, ostriches and emus, painful husbandry procedures, pigs, rodeos, sheep and beef cattle, slaughter of animals, temporary housing of companion animals, transport of animals and, zoos. Ministry for Primary Industries, Codes of welfare, https://www.mpi.govt.nz/protection-and-response/animal-welfare/codes-of-welfare/ (accessed 10 February 2019).

8 For instance, Andrew Knight, Uncaging New Zealand's Sows: Scrutinising Farrowing Crates (Save Animals from Exploitation (SAFE), 6 June 2018) at 20; and A Olsson, J Botermans, and J Englund, "Piglet Mortality - A parallel comparison between loose-housed and temporarily confined farrowing sows in the same herd," Acta Agriculturae Scandinavica, Section A - Animal Science 68, no I (2018): Introduction.

9 Including selecting for sows that display the traits of calmness and protectiveness; genetically selecting for smaller, healthier sows and smaller litter sizes; adequate environmental enrichment (including the provision of nest building material); increased space and hygienic and temporarily heated flooring; minimizing physical and social stressors; as well as the provision of design features that stimulate good maternal behaviour; and developing good human-animal relationships enabling the stock person to influence maternal behaviour.

I0 NAWAC response to the Petition of SAFE to end the use of farrowing crates, Submission to the Primary Production Select Committee, 27 July 2018 at 2.

I I Code of Welfare (Pigs) 20 I8, Minimum Standard No 6(b). This calculation is area (m2) per pig $=0.03 \times$ liveweight0.67 (kg).

12 lbid at 12 .

13 Poultry Standards Group and Guidelines Drafting Group. Layer Hen Cages, Supporting Paper Public Consultation Version (Australia: 20|6). 
I4 Gerard Hutching, "Behind New Zealand's Most Popular Meat," https://www.stuff.co.nz/business/farming// 0788883।/behindnew-zealands-most-popular-meat (accessed 10 December 2019).

I5 Hans Kriek of SAFE, interview with the author, 8 November 2019.

I6 Gerard Hutching, "Behind New Zealand's Most Popular Meat," https://www.stuff.co.nz/business/farming// 0788883 I/behindnew-zealands-most-popular-meat (accessed 10 December 2019).

I7 A Robins, and C J Phillips, "International Approaches to the Welfare of Meat Chickens," World's Poultry Science Journal 67, no 2 (20II): 355; and S Singh, HVerma, and D Chakraborty, "Ascites Syndrom, A Challenge for Blooming Poultry Industry," International Journal of Advances in Agricultural Science and Technology 5, no 6 (20 I 8): I0; and M Morris, "The Ethics and Politics of Animal Welfare in New Zealand: Broiler Chicken Production as a Case Study," J Agric Environ Ethics 22 (2009): 21.

I8 NAWAC, NAWAC Opinion On Animal Welfare Issues Associated with Selective Breeding, (New Zealand: Ministry for Primary Industries, 2017) at 16.

19 Code of Welfare (Meat Chickens) 2018,'General Information' section of minimum standard II (Providing for Behavioural Needs) and 'General Information' section of minimum standard 14 (Management of Health and Injury)

20 Code of Welfare (Meat Chickens) 2018, minimum standard IO(b) (Stocking Densities)

21 On the first reading of the Animal Welfare Amendment Bill 2013, 27 August 20 13, Mr Phil Twyford asserted that $38 \mathrm{~kg}$ of live weight per square metre in effect allows for 19 birds per square metre (as outlined in Gillian Coumbe, "Beyond Charlotte's Web - the blight of factory farming: An argument for law reform," (paper presented to the Auckland Women Lawyers' Association seminar, Auckland, March 2015) at 5, footnote 19). The Poultry Industry Association of New Zealand considers this figure to be somewhat lower at 15 chickens per square metre (Email from Michael Brooks (PIANZ) to the author, 9 December 2019).

22 A Robins, and C J Phillips, "International Approaches to the Welfare of Meat Chickens", 35I.

23 Ibid.

24 Ibid.

25 Ibid at 360.

26 NAWAC, Survey of Lameness in New Zealand Meat Chickens, New Zealand: Ministry for Primary Industries, 2013 at 23.

27 VTsiouris, I Georgopoulou, N Batzios, R Pappaioannou, Ducatelle, and P Fortomaris, "High stocking density as a predisposing factor for necrotic enteritis in broiler chicks," Avian Pathology 44, no 2 (2015).

28 Although no minimum standard explicitly states this, Minimum Standard No 6 provides that cattle "must be able to lie and rest comfortably for sufficient periods to meet their behavioural needs." Further, the Code states that cows prefer to lie on soft, dry and clean surfaces rather than hard, muddy, slipper or wet surfaces at I I. It also recognises that muddy environments are a contributing factor to lameness at 32.

29 Animal Welfare (Dairy Cattle) Code of Welfare 2019, Minimum Standard No 7 at 13

30 Animal Welfare (Dairy Cattle) Code of Welfare 2019, Minimum Standard 6(b) at II

31 New Zealand Veterinary Association, "Winter grazing", https://www.nzva.org.nz/page/wintergrazing (accessed 31 January 2020).

32 Including poor hoof health leading to claw lesions and lameness; increased risk of mastitis; birthing in mud; reduced lying time and poor quality of lying and sleep; reduced ability to ruminate; malnutrition and underfeeding; dehydration; cold and heat stress; lack of choice for lying site, fodder choice and social interactions; negative social interactions at high density (e.g. competition for feed, water and lying spaces); nutritional or metabolic problems; injury caused by fencing and equipment including fractures and broken legs due to mud; dental problems; and death resulting from misadventure, exposure or acute metabolic incidents. Winter Grazing Taskforce, Improving Animal Welfare on Winter Grazing Systems, 25 November 2019 at 3.

33 This is "a facility that incorporates a constructed base, and may or may not have a roof or walls. Off-paddock facilities include calf sheds,purpose-builthousingbarns forcows,stand-offareas orpads (including long-term wintering pads),andalso feed pads)."Code ofWelfare (Dairy Cattle) 20 I9,'Introduction'to Minimum Standard No 9 (Managing Dairy Cattle in Off-Paddock Facilities) at I 5. Code of Welfare (Dairy Cattle) 2019, "Recommended Best Practice"(g) to Minimum Standard 9 (Managing Dairy Cattle in Off-Paddock Facilities) at 18.

34 Ibid.

35 Rural News Group, "Keeping cows comfortable off-paddock", https://www.ruralnewsgroup.co.nz/rural-news/rural-farmhealth/keeping-cows-comfortable-off-paddock (accessed I 5 November 2019).

36 NAWAC, Report to accompany an amendment to the code of welfare for dairy cattle, 31 October 2019 at 21.

37 Ibid. 
38 Ibid; and G Olmos, L Boyle, A Hanlon, J Patton, J J Murphy, and J F Mee, "Hoof disorders, locomotion ability and lying times of cubicle-housed compared to pasture-based dairy cows," Livestock Science 125 (2009): 199-207.

39 Email from Mark Preece of New Zealand Salmon Farmers Association to the author, 23 March 2020.

40 These are outlined in further detail in NZALA's report, mentioned in the preamble to this article.

4I NZ Herald, "Kiwi's World Leaders in Pet Ownership", https://www.nzherald.co.nz/lifestyle/news/article.cfm?c_ id=6\&objectid=1 694903 (accessed 22 July 2019).

42 Stats NZ, "Agriculture", https://www.stats.govt.nz/topics/agriculture (accessed 7 October 2019).

43 Ibid.

44 Otago Daily Times, "Surge in chicken consumption prompts new testing probe", I 3 July 2020 https://www.odt.co.nz/business/ surge-chicken-consumption-prompts-new-testing-probe (accessed II July 2019).

45 Statista, "Number of pig livestock in New Zealand from 2010 to 2019," https://www.statista.com/statistics/9745।3/newzealand-pig-livestock-numbers/ (accessed II July 2019).

46 Figure.NZ, "Total hens for egg production on New Zealand Farms," https://figure.nz/chart/NJrkHqndarpsFDZa$33 \times 67$ SqoNoRsxCL3 (accessed II July 2019).

47 Sustainable Aquaculture, "New Zealand Aquaculture:A sector overview with key facts and statistics," https://www.aquaculture. org.nz/wp-content/uploads/20 I 8/08/New-Zealand-Aquaculture-facts-20 I 8.pdf (accessed I I July 20 I9).

48 Figure.NZ, "GDP breakdown by industry in New Zealand," https://figure.nz/chart/WRpSmBftC60IEu2q (accessed I I July 2019).

49 LEARNZ "Primary Industries in New Zealand," http://www.learnz.org.nz/primaryindustries | 72/bg-standard-f/primaryindustries-in-new-zealand (accessed II July 2019).

50 Ministry for Primary Industries, "New Zealander's views of the primary sector" (October 2017) at 83.

5I As outlined at sections 73(2)(b), 9(2)(a) and 10 of the Act.

52 Ministry for Primary Industries, About Us, https://www.mpi.govt.nz/about-us/ (accessed 27 April 2020).

53 For instance, no-where does NAWAC clarify how exactly it reviews the latest scientific literature and good practice. For example, what databases does it use? How does it ensure that its methodological processes are robust such that key information is not missed? How is it acknowledging and accounting for its own bias in the search for and interpretation of data? And how does it ensure that the independent peer reviewer is suitably independent and qualified to review NAWAC's report?

5415 December 2008 for the Code of Welfare (Dairy Cattle) 2019;20 October 2010 for the Code of Welfare (Pigs) 20I8; 29 June 2012 for the Code of Welfare (Layer Hens) 20I2; 12 October 20II for the Code of Welfare (Meat Chickens) 20I 8; 29 March 2010 for the Code of Welfare (Sheep and Beef Cattle) 20I8; 2007 for the Code of Welfare (Deer) 20l 8; I August 201 I for the Code of Welfare (Goats) 20I8; and 2013 for the Code of Welfare (Llamas and Alpacas) 2018. 